\title{
Post-ecological discourse in the making
}

\begin{abstract}
The purpose of this study is to take a discursive psychological approach to understand what has been called post-ecological discourse in European (especially German speaking) countries. In this study, it turns out that 15-16-year-old Swiss junior high school students constitute a microcosm of Swiss society as their discourse makes use of the same societal resources for talking about environment and environmental protection that have been identified for the society more generally. We provide four discursive features called interpretive repertoires and demonstrate how the interplay of these repertoires generates the post-ecological discourse of our students. Our analysis suggests that post-ecologism is a reaction to a lost locus of self-control in a Fact-oriented societal discourse. The shift towards a discourse of loss of control articulates personal agency in a rigid pragmatism that may be interpreted in terms of an environmental depression. The proposed methodological approach — using school settings as a laboratory for the analysis of societal discourse — may well be generalizable to many other research issues on the public understanding of science.
\end{abstract}

\section{Introduction}

Public understanding of science is often understood in terms of knowledge stored in the heads of everyday people to be sampled by researchers in a variety of ways independent of the language used. Discursive psychologists propose a different approach to knowledge, beliefs, and attitudes: These dimensions are topics and resources that everyday speakers mobilize while contributing to conversations (Edwards and Potter, 1992). From this perspective, therefore, what people say about a science related topic and how they say it is analyzed as a reflection of the possibilities that language offers to its speakers rather than as a reflection of their subjectivities (Roth et al., 2008). It is the account itself provided by the discourse that becomes "the primary object of research, 
rather than seeing it as a transparent representation of an individual's attitudes and beliefs or the true nature of events" (McKenzie, 2003: 4).

The purpose of this study is to take such a discursive psychological approach to understand what has been called post-ecological discourse (Blühdorn and Welsh, 2006) as it exists in Swiss society. Our past research shows that the discourse of 15-16-year-old Swiss junior high school students can be taken as a microcosm of Swiss society (Authors, 2009), using societal resources for talking about environment and environmental protection. That is, the discursive structure of our students' talk provides access to the features of a society's discourse more generally. In the present study, we explicitly focus on the post-ecologist aspect of Swiss discourse and on its discursive constitution. We show how its different dimensions emerge from the possibilities that language offers to its speakers. These possibilities are called interpretive repertoires.

In the remainder of this article, we begin by describing the concept of post-ecologism and its concrete reflection in Switzerland. We then introduce the definition of interpretive repertoires, provide the setting collection of our data and the four repertoires that we identified as the building blocks of our students' talk. In so doing we must keep to the very essential to give the most prominent space to our real goal in this article: to show how post-ecological talk emerges from the four repertoires.

\section{The concept of post-ecologism}

The socio-political framework of post-ecologism - the cultural background which our study describes - is one possible attempt to capture recent developments in the ecological consciousness of European, especially of German speaking countries. The basic claim of this concept is that Europe has entered an era in which "the historically radical and transformative elements of environmental movements and eco-political thought are blunted through mainstreaming and have been reconfigured by comprehensive cultural change" (Blühdorn and Welsh, 2006: 185). From this point of view, environmental 
concerns in European economics and politics recently have taken a position of unprecedented prominence. An abundance of eco-political measures are considered and on the way to implementation. However, and this is the core point of the post-ecologist diagnosis, "the key principles governing Western practices of production, circulation, exchange and consumption remain immutable" (Blühdorn and Welsh, 2006: 186). Consumer capitalism, infinite economic growth and wealth accumulation, always rejected by ecologists as intrinsically unsustainable remain untouched and operative. Whereas American anti-environmentalism tends to be based on exclusion and marginalization of ecologists' demands, the concept of post-ecologism captures the European coincidence of "the comprehensive success of the environmental movement and its comprehensive failure" (Nikel and Reid, 2006: 133). Talking about postecologism and not about post-environmentalism wants to underline the conceptual transition out of ecologism - a modernist ideology of unity, which assumes that there is only one nature, one global ecological equilibrium, and one intrinsic value of nature. Environmentalism, on the other hand, is seen as a pluralistic scenario of different ways to keep the environment (Blühdorn and Welsh, 2006).

Here, we are not concerned with the question whether Blühdorn and colleagues are correct in their analysis of European (especially German) environmental politics. Our previous research shows that the Swiss environmental situation indeed exhibits many of those aspects that Blühdorn and colleagues describe. For example, environment and environmental protection are indeed important concerns in Switzerland. More than two thirds of Swiss people buy local products to protect the environment and more than half of them support fair trade and low energy products and avoid wrappings (Nielson 2006). However, whilst in 1988 environmental protection was the most important societal concern for $74 \%$ of the Swiss, a dramatic decrease can be realized by 2006, when only $7 \%$ of Swiss people found environmental protection to be the most important issue in their societal agenda. Consumer attitudes on the other hand have become more and more 
important in Swiss society. For example, in Zurich—with 1 million inhabitants the biggest city in Switzerland $-80,000$ young adults (between 17 and 25 years old) say that "partying" is their favorite leisure time activity. Per year, Swiss young people on the average buy clothes for 1,000 to 5,000 Swiss francs. ${ }^{1}$

The environmental report “Umwelt Schweiz 2007” (BAFU and BFS 2007) produced by the Swiss federal government sums up the Swiss environmental situation by stating that the environmental situation of the country has stagnated during the most recent decade. Though constant progress has been seen in concrete aspects like water quality, waste disposal, and certain aspects of air pollution, this progress - mostly realized by political measures and technological innovation - has been constantly compromised by the increasing environmental pressure of the Swiss way of life and consumerism.

These lifeworld aspects indeed fit into the post-ecologist framework. It is however the associated discourse that we are interested in. Based on the theoretical approach of Blühdorn and colleagues, Nickel and Reid (2006) have postulated a list of 10 discursive aspects of post-ecologism (Table 1). Our analysis validates the existence of these ten dimensions and discursively constructs them using various combinations of the four fundamental interpretive repertoires.

\section{Method}

The discursive psychological approach

Interpretive repertoires, initially identified in scientists' formal and informal talk about science (Gilbert and Mulkay, 1984), have been used extensively in sociology and social psychology because they constitute something like a foundation in communication: Interpretive repertoires are the recognizable routines of arguments, descriptions and evaluations found in people's talk often distinguished by familiar clichés,

\footnotetext{
${ }^{1} 11,000$ interviews every second year, www.wemf.ch/de/print/machConsumer.php 2007
} 
anecdotes, and tropes. They are the building blocks through which people develop accounts and versions of significant events and through which they perform social life. (Reynolds and Wetherell, 2003: 496)

Interpretive repertoires are organized around specific metaphors and figures of speech (Potter and Wetherell, 1987). The collective consensus underlying a repertoire is so established and familiar "that only a fragment of the argumentative chain needs to be formulated in talk to form an adequate basis for participants to jointly recognize the version of the world that is developing" (Reynolds and Wetherell, 2003: 496). Accordingly, claims tend to be tentative whereas interpretive repertoires are taken as unassailable. This allows speakers to use repertoires in support of the claims they make. Thus, "recent research in science studies and social psychology showed that individuals in all walks of life constitute and support the factual nature of statements, beliefs, attitudes, and epistemologies by means of such interpretive repertoires" (Roth and Lucas, 1997: 145). The repertoires used by our students therefore do not merely reflect individual students' inclinations but they can be seen in fact as societal (cultural, linguistic) possibilities that students realize in a concrete manner because they can be taken as shared with all other members of the Swiss cultural setting (Roth 2005).

There are critics to the approach. Ethnomethodologists have critiqued this repertoiredriven form of discourse analysis, charging "that the in situ details of everyday life are ignored at the risk of reducing social life to recorded talk and conversational sequencing" (Holstein and Gubrium 2005, p. 488). However, we assume that the emphasis on the structure of talk itself can reveal the building blocks of our understanding how our students articulate their world, generally, and environmental situations, particularly. Other scholars in turn suggest that the interpretive repertoire approach fails to address the meaning speakers attribute to their talk (Milne 2009). But, following the approach that Ludwig Wittgenstein (1958) outlines, we take word-use to be the only relevant phenomenon in the making of sense (meaning). As a consequence, we abstain from 
pretending to be able to look into our students' heads, on the one hand, and to seek meanings that are somehow behind the students' words, on the other hand. Instead, we stay close to the linguistic material of the transcripts.

\section{The context of the study}

The research presented here originated in a survey made by teacher students of a University of Education. They wanted to find out what "their" students-15-16 year-old boys and girls of 47 school classes in Central Switzerland - thought about environmental issues. The results of the survey were overwhelmingly "pro-environmental." For example, more than $90 \%$ of these $15-16$ year-old students said that they found environmental issues important or even very important; and $62 \%$ asserted that they knew a lot about environmental issues.

To collect the data for the present study, we took the results back to three of the 47 classes that had been involved in the survey. The students talked about the results both in whole class discussions and in individual interviews. Two of these classes had provided above average positive answers to the survey, whereas one class had given belowaverage responses on critical issues. One class was from an urban region, one from a rural region, and one from a tourist region of Central Switzerland. As there are no private schools in Switzerland, the classes represented the social backgrounds of Swiss society generally. In each of the classes, there were about 20 to 25 students.

In each of the three classes, we presented the class results of the survey on six transparencies and compared them to the means of the other 47 classes. In so doing, we were not concerned with the results of the survey as such, but used them as a topic of and backdrop for whole-class discussions. Each videotaped whole-class discussion lasted approximately 45 minutes. Based on an initial viewing of the tapes, we additionally chose 12 students for in-depth, videotaped interviews. We selected students following 
1985): they were willing to express themselves without hesitation, gave interesting, largely consenting, or controversial answers during the class discussion.

\section{Interpretive repertoires for articulating the environment and environmental protection}

Concerning the topic of environment and environmental protection, our analyses revealed the salience of two core repertoires and four second-order repertoires. We call the two core repertoires the commonsense repertoire and the agential repertoire. Each of these split into two second-order repertoires: the commonsense repertoire resolves into the folk science repertoire and the folk psychology repertoire whereas the agential repertoire divides into the pragmatist repertoire and the control repertoire.

\section{The commonsense repertoire}

The commonsense repertoire reflects the argument that everyday knowledge falls into folk or commonsense theories. Here, "theory" does not mean "scientific theory." A commonsense (folk) theory is theory-like insofar as it is resistant to counterevidence, committed to ontological beliefs, pays attention to domain-specific causal principles and is coherent in its construction of the outer world. Speakers draw on the commonsense repertoire when it comes to the interpretation and classification of experiences in the

world. The relation to the outer world is framed in two dialectical tensions: me|thing and me|you. The commonsense repertoire consequently splits up into two partial repertoires: the folk science repertoire, and the folk psychology repertoire.

Folk science repertoire. In mobilizing the folk science repertoire, students draw on observations that can be made in the everyday world or in the media, or on topics that they know from science courses. The results of these observations are taken to be Facts, etymologically meaning things, events, or occurrences that have really and undeniably occurred and therefore constitute truths. 
A core metaphor for the folk science repertoire is the machine (Luhmann, 2004). A machine is identified by its elements and their interaction. The collective consensus behind the folk science repertoire is that if one knows these elements and their interaction in terms of input, operation, and output, then one understands the "system," it functions and it controls. The result of machine-like accounts drawing on the folk science repertoire is a mixture of personal observations and scientific Truths known by authentic testimony rather than by inferences and synthetic judgments, linked together by "folk physical" (causal logical) argumentation. The following excerpt from a classroom discussion illustrates the folk science repertoire. Albert, the interviewer, had asked one of the students, Justin, if he sometimes reflects about environmental issues. This is what Justin answers:

Justin: Well sometimes I do reflect about that, especially in context of the weather. These situations, when the weather is so extreme, it shows you a bit, what one should have done. And one could still do it, of course. That becomes clearer to you and you see it also frequently on TV.

Albert: What does it mean, "sometimes"?

Nicole: I mean, when one suddenly realizes, that the situation is different, for example in context of the floods. Then I suddenly started to reflect, if it had also come this way, if we had acted differently.

The folk psychology repertoire. The second repertoire emerging of the commonsense repertoire is created by the me|you tension. Speakers draw on it to understand and predict other persons as they interact with them. In such interaction, every member of society is a lay psychologist (sociologist) drawing on available linguistic and cultural resources that make something like a folk psychology: "Folk psychology involves our everyday understanding of how people work (how actions are caused by mental/intentional states)" (Baron-Cohen et al., 1999: 476). The collective consensus underlying the folk 
psychology repertoire is that one can use commonsense theory of mind to constitute the "you" and to predict his/her action. The following fragment, in which Nora talks about women and how they are better in realizing the importance of environmental issues, exemplifies this repertoire.

Nora: I tend to think that women get that better. Men always have different things in their heads. Men also like cars. They somehow are on a more playful way. We women want to have once a fixed home base, right. Children and so on, not every woman, but most of them, and so one is constrained in some way. The housewife is also more at home, right. They can read the papers and are more confronted than a man, going to work every day at seven o'clock.

\section{The agential repertoire}

Our second core repertoire draws on the argument that things do not happen without actions and that humans have the power to act (agency), which allows them to act in and transform their social and natural worlds.

The pragmatist repertoire. The pragmatist repertoire emerges from the tension of the ideal|real dialectic with respect to the context. As in other dialectical situations, the pragmatist repertoire expresses itself differently when students consider some situation as part of the ideal world or as part of the real world. In the ideal world, one kind of action could be taken; but in the real world, full of contingencies, a different set of action is appropriate. Thus, even if there are more preferable actions in an ideal world, these are not taken because in the given circumstances a worse action may be required to reach desired objectives. In the following fragment, Fabian uses the pragmatist repertoire when arguing why people keep going on with consumerism:

Fabian: It is for sure, that we destroy our world by our consumerism. By driving cars, and so on. But it is necessary. Otherwise there would be no more work. For example, if we were no more cars driving at all, there would be problems 
with the jobs. One couldn't work anymore. Or [take] a farmer who is driving a tractor. Of course, you could cut the borders by hand, where at the moment you use a power saw. But it is a question of convenience. And clothes, everybody needs cloths. Clothes get older, are used, get holes.

The control repertoire. The control repertoire sublates the opposition of self and other in a self|other dialectic with respect to agency. That is, in the same way as the pragmatist repertoire, the control repertoire harbors a tension, here between individual agency (self) and the agency of others. The control repertoire thematizes the relationship between what a single individual can do and does, on the one hand, and what the group/society s/he lives in can do and does, on the other hand.

In our analysis, the relationship between the two forms turns out to be mostly antagonistic, just as that between the ideal and the real. The locus of control then lies outside of the specific individual. S/he cannot act in the way she would like to because the group as a whole is overpowering. Following a question in which the interviewer thematizes the impact of a single person on environmental issues, Michael draws on the control repertoire: “They are not useless, but they don't stand a chance like in the group. These unfortunately don't stand a chance."

\section{The making of post-ecological discourse}

In this section, we exemplify (Table 1) how the four described interpretive repertoires constitute the 10 dimensions of the post-ecologist discourse. In so doing, we describe more extensively one half of these dimensions and treat the other five dimensions more cursorily. We proceed by providing an example of every dimension in our students' talk and by analyzing this example in terms of the four repertoires. The discursive examples are deliberately chosen to illustrate how post-ecological talk emerges from the interaction of these repertoires. We underline ones again that we could also provide excerpts of our 
students' talk that neither fit into the scheme of post-ecologism nor are an upshot of our four repertoires. We abstain from doing so, because the intent of our research is not to describe the full variety of our students' discourse but to focus on the discursive mechanisms underlying the post-ecologist argumentation.

\section{Acceptance of the in principle relevance of environmental issues}

The attitude of general and full acceptance of the in principle relevance of environmental issues combined with the warning that despite all undeniable seriousness, the environmental crisis must not be overstated (Dimension 1, Table 1) is the first dimension of post-ecologism. This point consists of two aspects: (a) the acceptance of the in principle relevance and (b) the warning not to overstate the environmental crisis. The first aspect can be understood as a combination of drawing on the objectivist and on the pragmatist repertoire. Here is a first excerpt from one of our interviews.

Albert: Something impresses me, namely that you said we would destroy our world. Do you have this feeling?

Eric: Yes, so it is. We don't want it to be true, but so it is. We destroy it every day a bit more.

Albert: What are you thinking about? I mean there are few who have worded it so clearly, no?

Eric: Well, we have the greenhouse effect, the global warming, every day more cars are driving on the streets, especially in America and Japan nobody cares, here [in Switzerland] rather more. It's simply so, the profit grows more and more, the clearing of the woods.

The interviewer (AZ) starts this part of the discussion by referring to a remark of Eric during the class discussion, when Eric says that we destroy our world. Eric reassures once again that this is his point of view and, being asked to explain, lists a number of aspects: the greenhouse effect, global warming, expansion of traffic, growing of profit, and the 
clearing of the woods. In so doing, he draws on the folk science repertoire. In this case speakers articulate facts provided by the media, personal experience, and school science education. These facts are taken as reality and the step from "facts" to their scientific interpretation (the greenhouse effect, global warming) is omitted when drawing on this repertoire. The results are unquestionable Truths integrated in causal logical calculations ("more and more"). The result is a bad future. The argumentation pattern that emerges here goes like this: The facts about environment are bad and therefore environmental issues are undeniably relevant. Therefore, the general and full acceptance is a direct upshot of the imperative impact generated by the folk science repertoire. However there is another characteristic of this dimension, which can be seen in the following excerpt wherein we asked the student how important environmental protection is for her.

Andrea: Well, theoretically environmental protection would be very important. But in fact you cannot realize it at all. If you would always focus on environmental protection only, then the economy would be crashing. All the emissions, they are unavoidable. Atomic plants, we need them also, without there was no electric energy. We thus cannot care that much about the environment.

At this point the pragmatist repertoire is at work. By drawing on the pragmatist repertoire, students use realistic arguments in opposite to ideal stances that could be taken (i.e., "in theory"). Thus, even if there might be some more preferable actions (in terms of environmental protection) in an ideal world, these may not be taken in the real world because in the given circumstances a worse action (in terms of environmental protection) may be required to reach desired objectives.

The pragmatist repertoire often carries a mocking and ironic tone towards attitudes that are depicted as belonging to an ideal world. In the interviews, the tone of students' voices at times became even angry and aggressive, for example, when they discussed that 
a local shopping mall could not be built as intended because the Swiss Traffic Club, an ecologically oriented automobile club, politically intervened against this project.

\section{Replacement of the emancipatory subject-oriented notion of modernization}

The pragmatist repertoire also accounts for the production of the second dimension of the post-ecologist discourse (Table 1) which concerns the replacement of the emancipatory subject-oriented notion of modernization by an efficiency-oriented systemcentered understanding wherein technological innovation and change have been adopted as intrinsic values (Dimension 2). The above-mentioned construction of a new shopping mall, for example, which would be combined with a consumption and recreation area, stood in the discussion for innovation and change as intrinsic values. Interestingly enough, the students rarely provided concrete reasons why this project should be supported on a pragmatist level. It was the innate pragmatist impetus itself against "extreme" (idealistic) positions that implicitly drove their argument. Innovation and progress are values in themselves.

\section{Neo-materialist and consumption-oriented patterns}

The third dimension of post-ecologist discourse - the prominence of neo-materialist and consumption-oriented patterns — can be understood by noticing that students articulate the relation between environmental protection and a consumption-oriented lifestyle as uncontroversial by drawing on the intuitive repertoire. Take the following paragraph of an interview where a girl answers the question of the interviewer concerning consumerism and environmental protection:

Melanie: I think, our generation does not really care. All is cheap; one can buy low prize clothes. One does not think about environmental protection. One realizes that it is cheap, and the one buys it. ... This is simply how it is today. 
You do it simply, you buy the cheap clothes and you don't think about it any further.

Melanie says that her generation does not care about environmental protection when it comes to consume things. She describes the respective attitude using the example of buying clothing. The only factor that does matter is the price. If clothes are cheap, then people buy it. This is, how Melanie says, simply part of today's life. In describing the attitude of her generation towards consumerism, Melanie draws on the folk psychological repertoire. The students draw on it to understand and predict the behavior of other people as they interact with them. Drawing on the folk psychology repertoire, Melanie describes consumerism as an intrinsic part of today's lifestyle. She typically uses a grammatically impersonal form, which demonstrates the finalizing power of the folk psychology repertoire. This style resource is even enforced by the frequent interspersing of "simply." Using the folk psychology repertoire, consumerism is articulated in terms of undisputed normality. The students refer to "what can directly be seen," that is, to mind concepts that are so "by nature." It makes no sense to discuss these things, because one cannot change them.

There is another repertoire that is frequently mobilized in the talk about consumerism. In the following excerpt, Noah starts with the remark that to buy daily goods would not be a problem. But he then points out that consumption is the fuel of technological progress, that "one has to pay researchers, instruments, and development," that monetary investments are crucial to technical progress (he uses the term "Entwicklung" which in Swiss German connotes progress).

Noah: It depends on what one buys. Human beings have some basic needs, so if they would confine themselves to those, then it would work and it would be good. However the problem is, if we want to go on with technology, then we have to invest money. One has to pay researchers, to pay instruments, 
development, it is simply expensive. I mean, you can't simply stop the progress.

The analysis of this passage provides an important insight into the linkage of the pragmatist repertoire and the folk science repertoire. Basically, Noah's remark draws on the pragmatist repertoire insofar as it shows the typical structure of a pragmatist argumentation: The ideal situation would be when people did only consume basic goods. However in "reality" this would be a problem, because consumerism drives technical progress by the money it generates. The pragmatist repertoire thereby compares values: "ideal" versus "real" values. To draw the line of demarcation between ideal and real however, Noah draws from the folk science repertoire. "Real" values are rooted in the realm of science and technology, whereas "ideal" values are not. To pay researchers, instruments, scientific/technical development count as "real" values that do not need any further argumentation. Progress and development are reflections of techno-scientific facts and truths, and therefore need no further justification.

\section{Disillusionment about the participatory revolution}

The fourth dimension of the post-ecologist discourse concerns the disillusionment about the participatory revolution and increasing reliance on supposedly more efficient market mechanisms with concomitant calls for political leadership. In the next excerpt from a class discussion, the role of a single person in environment protection comes to be articulated.

Henrik: Well I think now, one person alone is nothing. You need lots of people who do it, a single person is useless.

Albert: So it makes no sense for a single person to do something?

Henrik: Sure, he can try to influence others. He can say something and then perhaps ((he shrugs his shoulder)). 
Gian: I think you can always do something. However if somebody has little power and little influence, then you've got to ask you if this has any effect.

Henrik points out that a single person's effort is useless and that it needs a lot of persons to generate an effect. Albert asks if it therefore makes no sense to make an effort. Henrik starts by negating this; however his verbal answer retreats into the shrugging of his shoulders. Gian supports him by saying, that the effect is a matter of power and influence. Here, the belief in an emancipatory subject is questioned by mobilizing the control repertoire. The students mostly draw on the antagonistic version of this repertoire, for which it is typical that the anonymous "others" stand in an oppositional relationship to the individual. It is the agential tension itself that brings about the antagonistic relation between Self and Other that blocks all sensible action to bring about improvements for the environment. The antagonistic version of the agential repertoire presupposes the locus of control in "the others."

How is the call for political leadership featured in this example? In the following excerpt, Dorian supports the skepticism as to the power of a single person forwarded by his peers. One group engaging in environmental protection-so he says-is useless. And then his proposal: the presidents of all the countries should join in doing something. His reason is that only then "an Eskimo in Lapland" will get to know environmental initiatives.

Dorian: I also find, one group, which should do something for environmental protection: this is useless. The presidents of all this countries should join at some time. I don't know, if for example America does something alone, then an Eskimo in Lapland will never get to know that they want to do something for the environment.

As he articulates the argument that things do not happen without actions, the student draws on the agential repertoire. But it is not the control repertoire this time, as one should suppose on face value. The rather scurrilous rationale forwarded by the student 
provides us the key for interpretation: Only if the presidents join in their efforts for environmental protection, an "Eskimo in Lapland" will hear about it. This is an organizational argument. The real backdrop of the argument is society, a giant machine that has to be steered towards environmental protection. When students speak about politics and politicians, they actually draw on the folk science repertoire. This is not as surprising as it seems at first glance because to look at the society as a system can be a scientific standpoint for social sciences. Politicians are thus not seen as representing power, but as experts of the social machinery.

Environment behind employment, security, economic growth, crime and immigration

In the same way, Dimension 5 of post-ecologism—Relegation of environmental issues on the political priority list to a position behind employment, security, economic growth, crime and immigration - can be understood as a hinging of the pragmatist and the folk science repertoire. Here is an excerpt of Michelle's answer to the question about the importance of environmental protection:

Michelle: Important. Well, I shouldn't say that it is very important to me. And also not, not at all. I say, there are simply more important things.

Albert: What are you thinking about?

Michelle: Perhaps it is silly, but first you should care for a little more peace in this world. This I find very important.

Michelle suggests that environmental protection is not a primary concern to her and "not, not at all [important]." For her, it is more important to care for more peace in this world. In fact there were many reasons advanced by the students to argue why in a real world environmental protection cannot be realized: absence of peace (personal and social peace, a peaceful world), racism and immigration problems, or poverty. Whenever students articulate these concerns, they draw on the pragmatist repertoire. They shape their values after "facts" provided and evaluated by the folk science repertoire. 
Institutionalization of environmental concerns

Being overwhelmed by the blocking antagonism of the others, the materialization of agency is often attributed to impersonal powers. Environmental concerns are institutionalized (Dimension 6, Table 1). Answering the question about the personal attitude towards environmental protection, Noah does not downplay the role of personal attitudes. However he argues that personal ecological efforts are not enough. It needs, so he says, the impact of the economy, of the state. This is an instant of the folk science repertoire in the sense of "social technology," and Noah is in fact the student we quote above talking about consumption fuelling progress and the need of politicians to coordinate ecological efforts.

Noah: Of course it needs another attitude. But attitude alone is useless. Only because I separate my waste, have sun collectors on my roof, that's not enough, we need technology. We need the economy and we need the money of the state.

Other students support him by proposing alternative institutionalized forms of activating enough people. The following is an excerpt of this sort. Michelle talks about the role of the individual. She starts by saying that the effort of one individual is futile and then proposes to use advertisements to mobilize people. However when the interviewer asks if she is sure that advertisements would be helpful she says that no and that perhaps one has to start a big event with people coming from every region of Switzerland.

Michelle: ((Laughs)) it is difficult. It is unnecessary. If only one person takes an effort, then it is unnecessary. Futile work. If you want to reach something, then you must do some advertising or something else. For that the others also start to reflect.

Albert: If you did some advertising: would that really be useful? 
Michelle: I think, it would not be very useful. Most people wouldn't read it, if you were to distribute flyers, for example. You had to make a big event, where people from all regions could come in. Then we would be plenty enough, perhaps.

This is an interesting passage because, again, on face value it could be misinterpreted as drawing from the control repertoire, which is certainly involved in the first term of the quotation. But the rest of the quote is pure "social technology," the reflection on how to mobilize enough people for a certain goal, may it be environment protection or something else, and thus an example of drawing from the folk science repertoire. In this technological argumentation the experts (Dimension 6, part 2) are hidden in the particle "one." Noah and Michelle talk in this impersonal form, when they are reflecting about the organization of environmental protection. "One" means: public relation people, technicians, politicians. We observe in the talk about politicians that they are articulated primarily as experts and not as power people.

\section{Ecological problems as scientific, technological, economic or managerial issues}

Another way of impersonalizing agency is exemplified in Dimension 7 of postecologism: Reformulation of ecological problems as scientific, technological, economic or managerial issues. Drawing on the folk science repertoire, the discourse articulates "technology" as "providing solutions" and — as the reverse side of the same coin — the change of attitude as a "no solution." Technology is a way of acting, of having a real impact on a real situation. This is exemplified in the excerpt that follows an exchange where the interviewer asks Benedikt to explain why he rarely is concerned with the ecological future.

Benedikt: Why, well concerning the cars and so they are about doing research, there with new hydrogen, or something that they want to do. So I needn't care about that. 
Albert: Then you believe actually in technology?

Benedikt: Yes.

Albert: Are there others also who believe in technology and that the problems will be solved by technology?

Mara: Well, yes, sure. They will do actually something. Something they always find out.

A: And you feel that, technology-wise, not by energy saving or something like that?

Mara: No, I don't think it.

Benedikt justifies his rarely worrying about environmental issues because "they" are doing research about new technologies and when Albert asks him if he "believes" in technology he confirms that he is doing so. When Albert asks whether there are others who equally believe in technology, Mara responds affirmatively: "Something they always find out." And when asked so, she confirms that she does not believe in "energy saving or something," but that she thinks the solutions will be "technology-wise." Here "they" stands always for experts. Experts generate facts that can be transformed into real, trustworthy agency to change the working of the societal "machine".

A change of lifestyle, however, is not articulated as a solution, as a way to act and to transform the social and natural worlds: In our database, students often reformulate environmental problems in terms of economic issues. A typical example of such a transformation during a class discussion ensued after the interviewer asks what should be done so that people would act more environmental-friendly.

Cédric: It's also a question of prize. When you go together with friends to a festival, there are cups made of degradable material, they vanish during some years. But they are simply more expensive. They cost twice as much as the plastic cups. Well, as a fifteen year old, you don't buy the expensive ones. 
Albert: The question is that environmentally friendly behavior often is also a question of opportunities. (Some are nodding).

Dorian: The environmentally friendly approaches, for example also the meat, are simply expensive. Then it is a question of personal finances. If you have to pay more, then you don't choose it.

Cédric says that environmentally friendly behavior often also is a question of cost and he provides as an example degradable cups sold at festivals that are more expensive and therefore not affordable to the kids. Albert echoes this argument and in so doing offers it to the discussion round. Some students approvingly nod and Dorian provides another example, meat, the organic version of which is more expensive. Such arguments occur frequently in our database; and these always draw on the pragmatist repertoire.

\section{Vision of a radically different ecological society}

Drawing on the folk science and the pragmatist repertoire, the students generally talk about technical solutions more than about behavioural changes in order to protect the environment. They voice deep scepticism about the vision of a radically different ecological society (Dimension 8), as can be seen in the following excerpt from an interview during an exploration of attitudes towards alternative visions. Melanie has just stated that she normally is not really concerned with environmental thoughts. When Albert asks, what Melanie thinks about a completely different attitude towards the world, Melanie says that it depends on one's attitude towards the environment and that most people hear something about it, but then do not care any more for some or another reason. Albert asks, if Melanie does not have a vision about a different world, and Melanie responds, "definitely not." She admits that she likes pure nature, but she also talks about not being able to imagine a world without cars.

Albert: So don't you think that we should have a completely different attitude to this world? 
Melanie: It is rather difficult. It depends on what sort of attitude one has towards the environment. Most people once hear something about it and then they forget it again, or one is not interested in, or one is not in the mood for.

Albert: So you don't have a vision about a different world, with for example no cars any more?

Melanie: Definitively not. I of course love it when there is no traffic or no cars, only nature. But I don't think that I would like to have that, somehow. Perhaps one would like to have this on holidays and so.

First, we notice that the questions are always asked on an individual level. Does Melanie believe in a different attitude towards the world respectively in a vision about a different world without cars? Melanie, however, pertinently talks about "one's" believes and "one's" attitudes. This is a reliable marker for the drawing from the folk psychological repertoire. The collective consensus behind the folk psychology repertoire is that one can use the mirror of the alter ego, that is, the commonsense theory of mind to construct the "you" and to predict his/her action. The students refer to "what can directly be seen," that is, to mind concepts that are so "by nature." It makes no sense to discuss these things, because one cannot change them. "One" forgets environmental problems or does not care about these; "one" would not prefer a world without cars, except perhaps on holydays.

Another important feature of this dialogue is the swap between "environment" and "nature." Concerning the topic "environment," students talk about the world as a (normative) good: they talk about it generally drawing on the pragmatist repertoire. However when they speak about "nature," the world generally is a (material) resource and students tend to use the folk science repertoire. In fact, the talk about nature is almost always the talk about a physical resource and the protection of nature is then seen in a light cast by the pragmatist and the folk science repertoire, combining physical facts and needs with pragmatist goals. 
Rejection of ecological idealism and dogmatic instance

The preceding also is the background of Dimension 9 of the post-ecologist discourse: Rejection of ecological idealism and dogmatic instance towards so-called political realism/pragmatism which asserts that we have no choice but to adapt to the supposedly non-negotiable imperatives of economic growth, technological progress and global competition. When Albert asks Tamara what she thinks about globalization, growth and progress, she spontaneously answers:

Tamara: This has never come to my head so far. I think it is in fact okay. One should do three steps, and not look back. If we bring new cars on the market, then they should work with gas and so on, that you should proceed slowly and then build it up. Well ((hesitates)) it is both bad and okay.

After saying that she has never reflected about this so far, Tamara says that it (globalization, progress, economic growth) is actually okay, because one should do "three steps ahead" instead of looking back, for example by using new technologies (gas) for cars. Then she changes in midst of the phrase the direction of her argumentation by saying, that one should "proceed slowly and then build it up." She ends her answer by hesitating and saying that it is "good and bad."

In our analysis we frequently encounter such hesitating and an ambivalent attitude vis-à-vis the mighty triad of "globalization, progress, and economical growth." One reason might be that it is problematic from the side of the interviewers to combine these three overarching terms in the same question. In fact many students, as Tamara, do not immediately grasp the sense of this question. Normally, when students talk about globalization, progress and economic growth, they used the pragmatist repertoire in combination with the folk science repertoire to provide positive reasons for supporting these aspects of modern life despite the hesitation. In the next excerpt, the discourse 
combines scientific facts, the idea of progress, and globalization in the folk science repertoire.

Albert: What do you say as tot he terms: globalization, progress, growth?

Marvin: Well I find these good.

Albert: Could you describe this a bit more?

Marvin: Well I am not really against it, that we go on with development. I think, it has almost only advantages.

Albert: Could you say to me a bit, what you consider as advantages of this development?

Marvin: Well for example ((medical)) drugs. That one can fix AIDS for example. And things like that.

Once again this shows the folk science repertoire in action. Anticipating the critical interpretation of "globalization, progress, growth," Marvin mobilizes positive (science) arguments by drawing on this repertoire.

\section{Radical ecologism and direct eco-political action as variants of terrorism}

Sometimes, the mobilization of the pragmatist repertoire comes along with latent irony. In an ideal world, ecological aims would be of prime importance. In a real world, however, economic goals overrule everything else. Sometimes the ironic stance toward the attitude of an ideal world turns into rather aggressive complaints about people who "have their heads in the clouds." On these occasions, students criticize left-wing and green politics as exaggerated, extremist, and destructive. We articulate the ironic or even aggressive tone towards "ideal" stances in the discourse of our students in term of the typical indignation towards the breaking of rules in the framework of interpretive repertoires. People who question the priority of economic goals and the importance of concerns other than ecological ones, or even obstruct them, break the rules articulated in the pragmatist repertoire. These people are therefore blamed for being dangerous to a 
prosperous society. The extreme version of that reaction pattern is a criminalization of radical ecologists and direct eco-political action as a variant of terrorism (Dimension 10). Our students do not go so far as to call them terrorists, but their aversion to this form of engaging society and the world was unmistakable, as seen in the following response to a question concerning Greenpeace.

Tobias: I'm not worried. They may do it. But they need a hellish amount of money for it. This actually annoys me. We are anyway quite a bit in debt, and we waste all our money, if we invest all the money in things like that. If we clear our forests and so, this is not good, clearly not good. But: we simply need it! We need wood for our furniture, our houses.

Tobias says that the activities of Greenpeace as such do not disturb him, but that he is annoyed by the "wasting of money" when we "everywhere invest money in things like that." As an example he provides the clearing of forests, which "is clearly not good", but unavoidable because "we need furniture, houses."

Once again we identify the characteristic combination of the pragmatist and the folk science repertoire. The ideal values (to engage in environmental protection) are weighted against the real values (not to spend money and make debts). In the example, the real values are articulated by means of the folk science repertoire. In the argument about the clearing of forests it can once again be clearly seen that "drawing on the folk science repertoire" is not the same as "providing a scientifically correct argumentation." Here the Greenpeace campaign, which is about the clearing of tropical forests, is (incorrectly) related to the clearing of Swiss forests (that are under perfect ecological supervision).

\section{Discussion: Interpretive repertoires are the building blocks of post-ecologist discourse}

This study was designed to exhibit the dimensions of post-ecologism in the discourse of 15-16 years-old Swiss students concerning environment and environmental protection. 
Our discursive psychological framework highlights the interplay between the different repertoires leading to the emergence of a new understanding of the various dimensions of post-ecologism. Our analysis elaborates on the interplay of the different repertoires to constitute the characteristics of the post-ecological discourse. However, our analysis does not only reveal the source of the 10 discursive dimensions of post-ecologism-i.e., the four interpretive repertoires—but also achieves a slightly different coloring when compared to the original description. The change in "color" provided by our analysis may be described in this way: Post-ecologism is not an active orientation toward materialism and hedonism, a backlash against the ideals of the green culture. Rather, it is a reaction to a lost locus of self-control in a common sense-oriented inner and outer world. This shift towards a discourse of loss of control articulates personal agency in a rigid pragmatism accounted for by the two/four interpretive repertoires that underpin current societal discourses about environment and environmental protection.

We may even go one step further and diagnose the lack-of-control discourse concerning the environment and environmental issues as the core of post-ecologism. Our analysis then is a demonstration of how the interplay of interpretive registers available with a language can directly mediate individual control beliefs. Locked in between the common sense repertoire in its two variations (folk science and folk psychology), on the one hand, and the agential repertoire in its two variations (pragmatist and control repertoire), on the other hand, speakers of the post-ecological discourse end up in the loss of their ecological control belief. This is not trivial, because "the perception of personal control is one of the most significant aspects of an individual's self perception" (Falomir et al., 2000: 443). Control beliefs are regarded as primary in determining decisions to act. They are prerequisites for the planning, initiation, and regulation of goal-oriented actions, and they are part of the self-concept. As such, they largely determine feelings of selfesteem, causing such emotional states as pride, shame, or depression (Flammer, 1995). We come to the perhaps surprising suggestion that post-ecologism might be an upshot of 
an environmental depression, based on the loss of articulated agency with respect to issues of control belief concerning the environment and environmental protection.

The folk science repertoire, especially combined with the pragmatist repertoire-folk science Truths combined with folk science Values-is very close to scientism. The discursive core of the environmental depression therefore could be a common sense variant of scientism. This is an interesting hypothesis because the talk of our students on environment and environmental protection is a salient example of informal reasoning concerning socio-scientific issues (Sadler, 2004) and questions socialement vives (Simonneaux and Simonneaux, 2009). By now, this way of "talking science" is accepted in science education as an important aspect of fostering public understanding of science in schools. Our analysis demonstrates therefore that public understanding of science may be biased towards scientism in and through the talk itself, that is, by the inherent characteristics of the folk science repertoire. This bias may have nontrivial consequences in terms of an environmental depression.

It is an interesting hypothesis that this mechanism might be found more generally in the process of public understanding of science. In the processing of scientific information through the folk science repertoire scientific facts can mutate into Facts with capital F (Latour, 1999). In the "folk physical" causal logical argumentation these Facts then cluster to an unquestionable and invariant Truth. The puzzling new aspect of this hypothesis is that it locates the source of Facts (with capital F) and Truth (with capital T) not in the scientists and science teachers, as it is frequently done (Aikenhead, 2000), but in the talk of the recipients of scientific information, the public (or in our case the students) as their discursive resources. This could be a promising and important strand of research to follow up.

\section{References}


Aikenhead, G. (2000). Renegotiating the culture of school science. In J. L. Robin Millar, Jonathan Osborne (Ed.), Improving Science Education. Philadelphia: Open University Press.

Baron-Cohen, S., Wheelwright, S., Stone, V. and Rutherford, M. (1999) “A mathematician, a physicist and a computer scientist with Asperger syndrome: Performance on folk psychology and folk physics tests," Neurocase 5: 475-83.

Blühdorn, I. (2005) “Social Movements and Political Performance. Niklas Luhmann, Jean Baudrillard and the Politics of Simulation," in B. Haas (ed) Macht-Performanz, Performativität, Polittheater seit 1990, pp. 19-40. Würzburg: Königshausen \& Neumann.

Blühdorn, I. and Welsh I. (2006) "Eco-politics beyond the Paradigm of Sustainability: A conceptual framework and research agenda," Environmental Politics 16(2): 185-205.

Cobern, W. and Loving, C.C. (2007) “An essay for educators: Epistemological realism really is common sense," Science \& Education 17(4): 425-47.

Edwards, D. and Potter, J. (1992) Discursive Psychology. London: Sage.

Falomir, J. M., Mugny, G., Quiamzalde, A. and Butera, F. (2000) "Social influence and control beliefs in identity threatening contexts," in W.J. Perrig and A. Grob (eds), Control of Human Behavior, Mental Processes and Consciousness: Essays in Honour of the 60th Birthday of August Flammer, pp. 443-55. New York: Lawrence Earlbaum Associates.

Flammer, A. (1995) "Developmental analysis and control beliefs," in A. Bandura (ed), Self-efficacy in Changing Societies, pp. 69-113. New York: Cambridge University Press.

Gilbert, G.N. and Mulkay, M. (1984) Opening Pandora's Box: A Sociological Analysis of Scientists' Discourse. Cambridge: Cambridge University Press.

Lincoln, Y.S. and Guba, E.G. (1985) Naturalistic Inquiry. Newbury Park, CA: Sage.

Hsu, P-L., Marshall, A., Roth, W.-M. and Guenette, F. (in press) “To be or not to be? Discursive resources of (dis)identifying with science-related careers," Journal of Research in Science Teaching.

Latour, B. (1999) Pandora's Hope: Essays on the Reality of Science Studies. Cambridge, MA: Harvard University Press.

Luhmann, N. (2004). Einführung in die Systemtheorie. Heidelberg: Carl-Auer-Systeme Verlag. 
McKenzie, P.J. (2003) Interpretative repertoires. URL: http://publish.uwo.ca/ pmckenzi/McKenzie.pdf (accessed 28 April 2009)

Milne, C. (2009). Interpretive repertoires as mirrors on society and as tools for action; reflections on Zeyer and Roth's A mirror of society. Cultural Studies of Science Education, 4(4): 1013-1022.

Nikel, J. and Reid, A. (2006) "Environmental education in three German-speaking countries: Tensions and challenges for research and development," Environmental Education Research 12(1): 129-148.

Potter, J. and Wetherell, M. (1987) Discourse and Social Psychology: Beyond Attitudes and Behaviour. London: Sage.

Reynolds, J. and Wetherell, M. (2003) “The discursive climate of singleness: The consequences for women's negotiation of a single identity," Feminism \& Psychology 13(4): 489-510.

Ricœur, P. (1992) Oneself as Another. Chicago: University of Chicago Press.

Roth, W.-M. (2005) Doing Qualitative Research: Praxis of Method. Rotterdam: Sense Publishers.

Roth, W.-M. and Lucas, K.B. (1997) "From "truth" to "invented reality": A discourse analysis of high school physics students' talk about scientific knowledge," Journal of Research in Science Teaching 34(2): $145-179$.

Roth, W.-M., Lee, Y.J. and Hwang, S.-W. (2008) “Culturing conceptions: From first principles,” Cultural Studies of Science Education 3(2): 231-261.

Simonneaux, L. and Simonneaux, J. (2009). Students' socio-scientific reasoning on controversies from the viewpoint of education for sustainable development. Cultural Studies of Science Education. DOI 10.1007/s11422-008-9141-x

Sadler, T. D. (2004) "Informal reasoning regarding socioscientific issues: a critical review of research," Journal of Research in Science Teaching 41(5): 513-536.

Wittgenstein, L. (1958) Philosophical Investigations. Oxford: Basil Blackwell. 